International Journal of Business and Management 4 (6): 01-08, 2020

e-ISSN: 2590-3721

(C) RMP Publications, 2020

DOI: $10.26666 /$ rmp.ijbm.2020.6.1

\title{
Green Management Strategy - An Initiative Towards Sustainable Practices
}

\author{
Raida Abu Bakar, Muhamad Azwandi Azlan \\ Department of Business Policy \& Strategy, Faculty of Business \& Accountancy, \\ University of Malaya, Malaysia
}

\begin{abstract}
The current efforts put on sustenance and sustainability has driven many organizations around the world to adopt environmental management practices which include all extents of green solution. While certain common tools and knowledge can be used to control, track and evaluate these green components in an interconnected element, they are generally managed on a piecemeal basis and under various management standards; and most frequently, as ad-hoc initiatives as opposed to programs. To date, pressure to practice sustainability efforts comes mainly from two main stakeholders - the management and the customers. This concept paper looks at the implementation of green management and sustainable green practices of one organization as a case study. It proposes that management has a role to play in helping to reduce negative sustainability impact. Two theories were proposed as the theoretical lens to give meaning to the research, but further research is required to support the findings of this paper.
\end{abstract}

\section{Key words: Green management, Green practices, Sustainability, Stakeholder and Signaling}

\section{INTRODUCTION AND PURPOSE}

Global climate change has become a significant policy issue for countries all over the world, both developed and developing countries. The triggers and effects of today's global warming constitute a great environmental challenge to mankind as they cut through every human being's life, a country and its economy and industries. If not given adequate attention, more natural disasters and tragedies would occur. In Malaysia, some of these mishaps can be traced to the disasters in the Highland Towers, Pos Dipang, Gua Tempurung, the dumping of radioactive wastes in Sungai Gatom in Johor, arsenic contamination in Gerik's Sungai Ganda Water Treatment Plant, the current catastrophe of Sungai Kim Kim. Others not included are the river pollution levels, deforestation, habitat degradation and other environmental impacts of the country. To overcome these tragedies from future happenings and to maintain and sustain the country's environmental habitat, more needs to be done, including Green culture and Green practices. Environmental degradation needs to be tackled urgently for the sake of invoking a sustainable business activity.

As a response to scientists' pressure and the government's increasing consensus to reduce the harmful impact of climate change, industries are beginning to make plans to address the issue of the carbon-constrained environment. This behaviour, however, is not universal among all the organizations which differ greatly in terms of cultural, technical, institutional and organizational barriers [1]. It had been mentioned by Venkatesh [2] that an individual starts from materialism (body), then a balance of the physical, emotional and spiritual progress in life before he/she can reach spirituality. Similarly, industrial ecology also needs to be addressed so as to achieve sustainability goals because the long-term economic benefits would lose their appeal while a spiritual outlook is indispensable for global sustainability.

In the international circle, there has been an increasing awareness over the past decade that climate change and global warming is one of the greatest challenges. All industries have shown a great interest in environmental issues [3]. This increasing global environmental concern, and the emergence of more international environmental standards, had generated more pressure for organizations to implement a structured environmental policy and program among themselves [4]. Thus, organizations around the world have no choice but to adopt these processes in order to address their sustainability practices with more efficiency.

The day-to-day practices of organizations and their effect on environment has also led to the desire to going green. Current practices show that many organizations have also volunteered to operate in a more environmentally friendly way, hence in the near future, 
the ideal could be "being green". Awareness of the green action can be seen in natural settings, such as green products, green technology, green education, and green life (the work-life balance).

The green philosophy was introduced to Malaysia in April 2009 through the establishment of the Ministry of Energy, Green Technology and Water during a cabinet reshuffle. The latest, Circular No. 2/2014 [5] was subsequently induced to strengthen the green principle, thereby highlighting the importance shown by the Government of Malaysia. In this regard, the National Green Technology Policy has described the definition of 'green technology' as the production and implementation of the products, equipment and systems used to preserve the natural environment and resources, mitigating and reducing the negative impact of human activities [6].

The adoption of the green culture was a global trend [7]. "Being green" became a very systematic mechanism in which the key goal of the company was to minimize costs, build energy usage, and reduce wastage of available resources or to create recyclable materials [8]. The Malaysian government invested billions of dollars in this move just to raise public awareness about environmental protection and green principles [9].

Green environmental protection and green principles is not a new concept. Research on this has been extensively studied, whether it is the individual environment or green behaviour within the household. In contrast, little research has been done to explore the employees' environmental behaviour within organizations [10]. Hence, this concept paper is very important for it aims to understand the consciousness of the employee, and following the outcome, it aims to make recommendations as the way forward. The outcome derived from this concept paper can be combined with current initiatives so as to develop a more positive direction that will help the Organisation, to achieve sustainability. The integration of a green management with the organization's everyday language, and work culture would enhance the practice. This would be more pronounced when the employees' awareness about green credentials increase and when they note that sustainability opportunities are feasible and possible, particularly when implemented through creative methods and designs [11]. In that regard, this concept paper seeks to fill the void by finding out what is understood as the Green policy, and what instruments or resources would be included in the policy if it were formulated.

A systematic measuring tool is necessary for ensuring that there is a systematic and adequate procedure for auditing the environmental dimension. This has to be in place, and regularly used by the top management to evaluate the practices. The management process of the
Green practice (practice leaning to environmental sustainability) was implemented through the establishment of the ISO 50001 and ISO 14001 which was specifically formulated for electricity consumption and environmental conservation [12][13]. Although there were numerous studies done on energy management and environmental conservation via the ISO50001 and ISO14001, a holistic method for the management of sustainability in the context of an organization is still lacking. Therefore, an integrated system which can manage the sustainability aspects of an organization and can also promote cleaner production is very much needed. Such a system should encompass the key elements of sustainability; it should also comply well with the ISO standards related to sustainability so as to allow organizations to integrate sustainability aspects in their existing ISO system, seamlessly.

In this regard, a systematic, integrated, and efficient approach for collecting, monitoring, analysing and managing information and resources via the Green Management would be most beneficial. Doing so for the organization, would not only lead to organizational sustainability, but also its potential to save ample resources, reduce significant redundancies, promote cleaner productions, and enhance the effectiveness and efficiency of the organization.

Further to all the above, this concept paper also seeks to explore the organizational pressures and demands made by various stakeholder groups, such as the top management, the Operational level and the Tactical level, all of which can be quite challenging to manage. This issue was stressed by Guerci, et al. [14] who posited that the number of firms engaging in green and environmental practices is growing as a result of the pressures created by various stakeholders. Some studies also explained how stakeholders' pressure on firms had led to their adoption of more environmentally friendly practices so as to improve environmental performance [14]. Based on this, it is therefore important to understand how stakeholders' pressure may impact on the experience of the managerial level. This concept paper looks at the role of stakeholder pressure in affecting green management practices; it also seeks to understand how these pressures may or may not improve environmental performance in the organization.

In particular, operational demands and environmental protection challenges are an increasing trend. Responding to the current situation, most organizations had formulated some creative and innovative Transformation Programmes. The aim of this programme is to consolidate the working requirements without reducing the number of employees or even their operational capabilities. Such a consolidation strategy is able to provide organizations with significant efficiency 
savings. Many of the more established organizations have experienced a decade of transformational process where they even took on the practice of adopting new trends that are very valuable and important. Nonetheless, this concept paper argues that the lack of a management system which can help to sustain and maintain this culture within organizations would lead to extra costs in the future. The crucial role of this research is to propose a framework for green policy which encompasses a sustainable management system that takes into consideration many issues, such as the efficiency of the system, the cost saving matters, and the role of the managerial level in ensuring the success of this process.

The lack of dynamic information and interactivity can hinder the employees from gaining an in-depth understanding of the green concept. Due to the lack of guidelines, and also lower environmental awareness [15], many employees are still unclear about the concept of green practices. Moreover, the implementation of the green initiative needs to be in line with the existing Environmental Management System proposed by the government. This includes commitment, policy, planning, implementation, measurement and evaluation followed by reviews and improvement [16]. A Green Strategy Initiative can be used as a measurement tool to gain sustainability in the working environment, if implemented.

In today's world of globalization and climate change, going green is no longer an option. It is rapidly becoming an imperative move for individuals and organizations. Due to this, the current concept aims to offer a significant platform which can be used by organizations such as the Government Agency in Malaysia, to shift the mindset of the people, moving them away from their normal life routine to a routine that has a quality life culture. This concept paper offers to be the platform that can be used to educate the Naval community, and to increase their green behaviour. Since there is a requirement for the naval community to deal with strategic assets, this concept paper will also provide input for the Naval community to increase its competency and to improve its success rate in implementing sustainable initiatives. The input provided by this concept paper could be used in the planning of the requirements that must be followed during the initial stage of developing each strategic asset.

\section{THE ESSENCE OF IMPLEMENTATION}

Green practice is the stepping stone to develop a quality working environment; it is an essential process for improving environmental performance that aims for sustainability [17]. The first contribution of this concept paper is the methodological aspect of the process used in this study, which is the interpretive approach. The aim is to understand how Green practices among the employees can improve environmental performance. Since not many studies had been conducted on Green Management and Green practices in Malaysia [18], this concept paper also contributes to knowledge by focusing on the effectiveness of green practices and its role in sustainability, thereby establishing a conceptual model which can be used within the Green Management.

The second element of this concept paper is to discuss the role stakeholders adopt in Green practices by understanding the Stakeholder theory. This is an important aspect because understanding the psychology of the internal stakeholders for Green practices would allow the researcher to explore the stakeholders' consequences in adopting Green practices. Through understanding their awareness and experiences on Green practices, this concept paper would shed some insights into knowing how Green practices promote green behaviour and a quality working environment.

The third element of this paper talks about the signaling theory which aims to understand the phenomenon of Green practices. Signaling is important for implementing Green practices. Without signaling, Green practices might be ambiguous and unclear. Therefore, it is essential to find out whether the employees had received clear signals in order to synchronise the understanding of the practice from top management to the bottom ladder of the organization. The efficiency of signaling will determine the success of the organization in adopting Green practices.

Lastly, this paper also focused on the organizational benefits that can be derived from sustainability. It would establish a framework for implementing sustainable operations. The study will also provide the valuable assistance for sustainability, and for maintaining strategic assets in the higher degree of readiness. The other future values which can develop and strengthen the Green initiatives are to get better value for money, to promote sustainable management of resources, to promote the supply of green products and services, to encourage innovation among stakeholders, to enhance environmental awareness, to reduce energy consumption and to reduce wastage.

\section{LITERATURE REVIEW}

An increasing body of literature has outlined the synchronization of existing theories within the perspective of green management and sustainability practices as a means to establish a good platform for research ideas. It appears that successful environmental management has not only been shown to yield sustainability achievements, but also support general 
firm performance [19], and innovation in organizations [20]. Organizational practitioners have been concerned about environmental issues [21], and today, they have accepted that "being green" makes good business sense [22]. Moreover, as noted by Unsworth, Dmitrieva and Adriasola [23], there is accumulating evidence to show that the success of organizational initiatives for environmental sustainability hinges upon the individual employees' behaviour. For example, research has proven that employee behaviour makes significant contributions to organizational environmental performance [24], and waste reduction and cost saving [25]. This implies that environmental strategy is a between-persons variable; it refers to employees' awareness of and knowledge about their organization's strategy and approach regarding environment sustainability [26].

\section{Green}

Green is the colour of nature which symbolizes growth and living, hope, symbol of productiveness, security and freshness [27]. It was noted by Opatha [28] that green is related to the environment, hence it also means preserving and conserving a natural environment, minimizing environmental pollution, and generating natural-looking zones or places. A Green workplace is hence, one that is environmentally sensitive, resource efficient, and socially responsible [29]. The management of organizations must understand the benefits and opportunities of going green, which is a step taken towards ensuring the success of green efforts [18]. It thus appears that organizations that consider themselves to be responsible towards environment need to act as agents of change; they need to be more aware of what it means to practice environmental sustainability [30]. For example, The Navy, as purported by the management to be Green Navy, is one such organization, thus it serves as a valuable ground for initial research in green environmental issues. Since there is a dearth of research in the area of green management, it is pertinent to understand the practices of the employee in Malaysia and their adoption of the Green concept in their routine as well as their working environment.

\section{Green Management}

The definition of Green Management refers to the procedure that most companies use in developing environmental management strategies for offsetting industrial growth, and for safeguarding the natural environment for future generations [31]. This notion is not only a strategic and dominant issue for businesses, it is especially useful to multinational enterprises which use this concept as a mechanism to operate their businesses globally [32]. The increasing level of environmental consciousness and environmental pollution has led many public actors and regulatory bodies to expand on the existing environmental law. As a result, more firms are investing in environmental management systems so as to improve their reputation whilst also reducing the risk of environmental disasters [33]. This practice promotes sustainability, both for the environment and the industry.

\section{Organizational Sustainability}

The most popular and most well-adopted definition of sustainability is derived from Brundtland Commission [34] who said that sustainability is, "the development that meets the needs of the present without compromising the ability of future generations to meet their needs". The term, sustainability, was defined as an integrative concept that considers environmental, social, and economic aspects as the three fundamental dimensions; also denoted as the three pillars of sustainability [35]. It was also proposed by [36] that sustainability can be divided into four degrees of: weak, intermediate, strong, and absurdly strong, depending on how much substitution one thinks there is among the types of principal. Sustainability can be a broad aspect. It could be in the context of global sustainability [37], country sustainability [38], or organizational sustainability [39]. Based on this, the current concept paper will focus on the elements of organizational sustainability, which was defined by Smith and Scharicz [40], as the result of the activities of an organization, voluntary or governed by law, and which demonstrates the ability of the organization to ensure that business operations are viable whilst not negatively impacting on any social or ecological system. In the spirit of this aspiration, it is important for an organization to venture into Green practices in order to maintain itself as a relevant organization whilst playing its significant role as a player in this country.

\section{Green Management and Sustainability}

Notwithstanding, the global economic slowdown has further impacted on the government budget, thereby affecting many organizations. It is difficult for the government to meet the demands of the public services and security agencies. Organizations and agencies including those in the services are currently competing among themselves for the limited budget and scarce resources. Therefore, the Green Management initiative is a tool to overcome and mitigate these types of issues and challenges. Ultimately, it is crucial that the organizations have a clear level of awareness and understanding in order to achieve organizational sustainability.

Sustainability is a significant and contemporary issue to policy-makers, public opinions and practicing managers [41]. Therefore, the Green Management initiative can become an important element and tool for supporting organizational objectives. It also appears that Green 
Management initiative is an essential effort to encourage and provide visibility for research and practices in view of organizational sustainability.

\section{UNDERPINNING THEORIES}

\section{Stakeholders Theory}

The stakeholder theory was developed by Freeman [42], with most scholars embracing an inclusive approach which suggests that any organization or individual can be a stakeholder. Mitroff [43] defines stakeholders as the interested groups, parties, actors, claimants, and institutions, both internal and external to the corporation, that exert a hold on it. This means that stakeholders are all those parties who either affect or are affected by a corporation's actions, behaviour and policies. On the question of who is a stakeholder, generally, the trend in environmental conflict literature seems to be inclusive in nature, trying to accept a large number of individuals and organizations as stakeholders [44].

Another definition of stakeholder offered by Freeman [42] states that a stakeholder in an organization is any group or individual who can affect or is affected by the achievement of the organization's objectives. Bryson [45] argued that the nominally powerless is also deserving to be considered, hence a stakeholder is, "any person, group or organization that can place a claim on the organization's attention, resources or output, or is affected by that output" [45]. Returning to the government agency staff as context, it appears that the organization is still in the process of thinking and working smart; it has to do more with less so as to avoid doing more of the same thing, and to be more vigilant about stakeholders' expectations and perceptions [46]. Based on this, the current concept paper intends to use the stakeholder theory as its underpinning philosophy so as to learn about the employees' awareness, and to understand the various stakeholders' perspectives within the organisations in adopting Green Management initiatives.

\section{Signaling Theory}

The Signaling theory was introduced by Spence [47] who used it to analyse the labour market, and to observe how a job candidate engages in a particular behaviour which reduces information asymmetry. Potential employers may not have a clear understanding about the quality of the job candidates. Therefore, candidates need to obtain soe education to signal their quality, thereby reducing information asymmetry. Moreover, it can be ambiguous as to whether the applicants would be chosen by employers. This situation was explained by observable attributes, such as education, and working experience, both of which are known as signals [47]. These signals were defined by Spence [47] as characteristics that are attached to an individual which is subject to manipulation. Specifically, when potential employers lacked information about the quality of the job candidates [48], they need to refer to more tangible references. The Signaling theory has been used to address various issues of information asymmetry between two parties [49]. It was explained by Stiglitz [50] that information asymmetries happen when "different people know different things". This is because, some of the information can be private, thus information asymmetry arises between people who hold the information [51]. According to Connelly et al. [51], the Signaling theory should be extended to other boundaries so as to include perspectives of the management.

Previously, the Signaling theory was mainly used to examine the process of sending a signal to external stakeholders, such as shareholders, customers, and competitors [52]. Later, other studies began to focus on internal signaling between organizations and employees, for example, performance management [52]. It was posited by Biron et al. [52] that signaling is a process of interaction between an organization and its members, such that they choose, design and implement their own practices together. In this concept paper, signaling is deemed to exist when organizations are trying to promote certain practices which are then perceived by the employees as signals. Therefore, Green practices can be viewed as signals that are used to send messages to the employees. Specifically, Green practices is important as it can serve as signals of organizations which support, trust and are committed to their employees.

\section{Green Activities and Signaling Theory}

Green activities encourage more employees to be part of the Green practices. A clear Green mission and vision enables the organization to engage its employees in environmental issues [53]. Activities that support environmental goals are able to stimulate employees towards giving more suggestions, thereby empowering them to improve their environmental performance [53]. By applying environmental goals into the corporate culture and strategic plans, organizations are sending signals about their commitment towards environmental issues [54]. In addition, Green activities also serve as an indication to the employees about the working conditions in the organizations concerned. Indirectly, Green activities may also send signals to the management level that their organizations care for the employees' well-being and welfare.

\section{Signaling Theory and Response}

The effectiveness of organizations' signaling in reducing information asymmetry, however, depends on the accuracy of the signals received, and the 
interpretation of the signals [48]. More importantly, if receivers were not looking for signals, then the process of signaling would have been wasted. Further, the effect of signaling could be different for different individuals. Based on this, it is important to get feedback from receivers so as to make the signaling process more effective [55]. To obtain a comprehensive understanding on how Green practices send signals to the employees, it is important to gather the feedback of the employee through social interactions. In this regard, the gap which this concept paper aims to close is to explore the effectiveness of Green practices in signaling to the employees to improve their working environmental performance. Figure 1 below further illustrates.

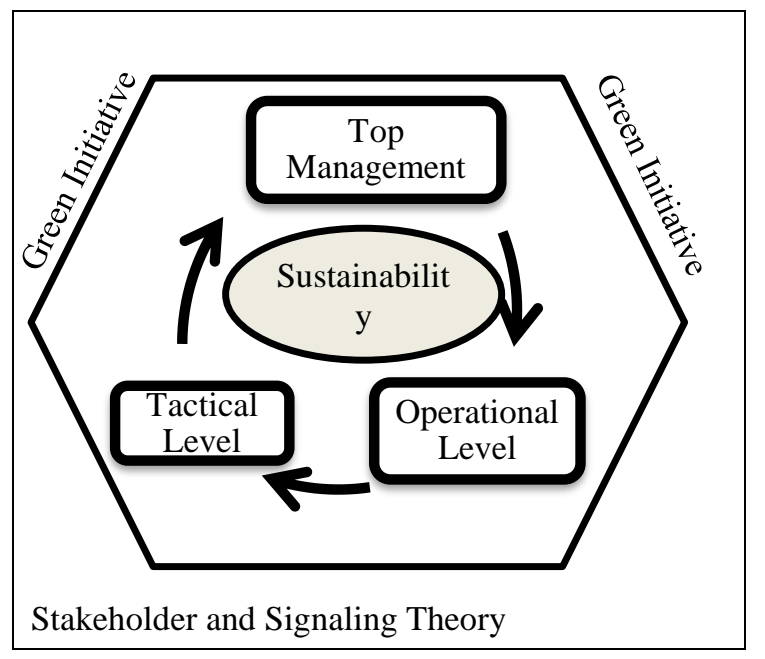

\section{CONCLUSION AND FURTHER RESEARCH}

Environmental culture is the gateway to the organization's competitive advantage. This happens because the topic of Green practices has already become an important issue for many organizations. Being Green needs the management of environment to be integrated into management practices. For this to happen, the department of strategy must reflect and inspire the ambitions of the commanding team, and other employees. It then needs to algin the implementation with the strategy, values and culture of the organization. Doing so would enable the organizations concerned to deliver sustainable returns to the country, address current needs, identify and respond to emerging societal trends, respond to governmental and regulatory expectations and henceforth, influence the public policy agenda. Green practices, as a concept, should be translated into the daily processes [56] because it would give some advantages to the various organizations to develop the Green culture.

A Sustainable Green Management framework has been proposed to manage the sustainability elements of an organization. The procedure involves integrating the managerial level and sustainability related key elements. These insights can assist facility managers to implement conservation programmes effectively, thereby enhancing future sustainability. Among the key benefits of implementing the framework within the management and integrating it with the management system is the benefit of being focused and having a clear vision of how the framework contributes towards sustainability goals, costs and time. It also reduces redundancies, while simultaneously enhancing productivity. Furthermore, an integrated management system would also reduce the time taken for organizations to document preparations, prepare manpower for document controlling, find costs for internal and external audits as well as encourage the facility managers to implement action plans for cleaner productions.

\section{REFERENCES}

[1] M. T. Küçükoğlu and R. İ. Pınar.(2015). Positive influences of green innovation on company performance. Procedia - Soc. Behav. Sci., vol. 195, pp. 1232-1237.

[2] G. Venkatesh. (2010). Triple bottom line approach to individual and global sustainability. Probl. Ekorozwoju, vol. 5, no. 2, pp. 29-37.

[3] Bangwal, Deepak \& Tiwari, Prakash. (2015). Green HRM-A way to greening the environment. Journal of Business and Management. 17. 45-53.

[4] Sudin S. (2011). Strategic Green HRM: A proposed model that supports Corporate Environmental Citizenship. International Conference on Sociality and Economics Development, 10, $79-83$.

[5] Treasury Circular Letter No2/2014. (2014).

[6] Ministry of Energy Green Technology and Water. The National Green Technology Policy Report Malaysia. pp. 1-26, 2009.

[7] R. Deepika and V. Karpagam. (2016) A study on green HRM practices in an organisation. Int. J. Appl. Res., vol. 2, no. 8, pp. 426-429.

[8] Jafri, S. (2012). Green HR practices: An empirical study of certain automobile organizations of India. Human Resource Management, 42, 6193-6198.

[9] Ministry of Finance. (2017). Budget 2017. www.nst.com.my/news/nation/2017/10/295824/ 2018-budget-govt-invest-rm5-billion-greentechnology, 2017.

[10] D. Manika, V. K. Wells, D. Gregory-Smith, and M. Gentry. (2013). The Impact of Individual Attitudinal and Organisational Variables on Workplace Environmentally Friendly Behaviours. J. Bus. Ethics, vol. 126, no. 4, pp. 663-684.

[11] F. Testa, O. Boiral, and F. Iraldo. (2018). Internalization of environmental practices and 
institutional complexity: Can stakeholders pressures encourage greenwashing?. J. Bus. Ethics, vol. 147, no. 2, pp. 287-307.

[12] Department of Malaysia Standard MS ISO 50001, MS ISO 50001:2011 - Energy Management Systems. (2011).

[13] Department of Standard Malaysia MS ISO 14001, MS ISO 14001:2015 - Environmental Management Systems. (2015).

[14] M. Guerci, A. Longoni, and D. Luzzini. (2016). Translating stakeholder pressures into environmental performance - the mediating role of green HRM practices. Int. J. Hum. Resour. Manag., vol. 27, no. 2, pp. 262-289.

[15] J. Y. Yong and Y. Mohd-Yusoff. (2016). Studying the influence of strategic human resource competencies on the adoption of green human resource management practices. Ind. Commer. Train., vol. 48, no. 8, pp. 416-422.

[16] M. Hasan and C. K. Chan. (2014). ISO 14000 and its perceived impact on corporate performance. Bus. Manag. Horizons, vol. 2, no. 2, p. 1 .

[17] S. Cheema and F. Javed. (2017). The effects of corporate social responsibility toward green human resource management: The mediating role of sustainable environment. Cogent Bus. Manag., vol. 4, no. 1, p. 13.

[18] Yusoff, Y. M., Othman, N. Z., Fernando, Y., Amran, A., Surienty, L., \& Ramayayah. (2015). Conceptualization of Green Human Resource Management: An Exploratory Study from Malaysian-based Multinational Companies. International Journal of Business Management.

[19] H. Younis, B. Sundarakani, and P. Vel. (2016). The impact of implementing green supply chain management practices on corporate performance. Compet. Rev.

[20] C. H. Chang and Y. S. Chen. (2013). Green organizational identity and green innovation. Manag. Decis., vol. 51, no. 5, pp. 1056-1070.

[21] T. A. Norton, H. Zacher, S. L. Parker, and N. M. Ashkanasy. (2017). Bridging the gap between green behavioral intentions and employee green behavior: The role of green psychological climate. Journal of Organizational Behavior, vol. 38, no. 7, pp. 996-1015.

[22] Holme, R., \& Watts, P. (2000). Corporate social responsibility: Making good business sense. Geneva, Switzerland: World Business Council for Sustainable Development.

[23] Unsworth, K. L., Dmitrieva, A., \& Adriasola, E. (2013). Changing behaviour: Increasing the effectiveness of workplace interven- tions in creating pro-environmental behaviour change. Journal of Organizational Behavior, 34, 211229.
[24] Boiral, O., Talbot, D., \& Paillé, P. (2015). Leading by example: A model of organizational citizenship behavior for the environment. Business Strategy and the Environment, 24, 532550 .

[25] Tam, V. W., \& Tam, C. M. (2008). Waste reduction through incentives: A case study. Building Research \& Information, 36, 37-43.

[26] Ramus, C. A., \& Steger, U. (2000). The roles of supervisory support behaviors and environmental policy in employee 'ecoinitiatives' at leading-edge European companies. Academy of Management Journal, 43, 605-626.

[27] S. Prasad, D. Khanduja, and S. K. Sharma (2016). An empirical study on applicability of lean and green practices in the foundry industry. Journal of Manufacturing Technology Management, vol. 27, no. 3, pp. 408-426.

[28] H. Opatha (2013). Green Human Resource Management A Simplified Introduction.

[29] Sathyapriya, J., Kanimozhi, R., \& Adhilakshmi, V. (2014). Green HRM-Delivering high performance HR systems. International Journal of Scientific Research, 3, 31-34.

[30] C. J. C. Jabbour, F. C. A. Santos, and M. S. Nagano. (2008). Environmental management system and human resource practices: is there a link between them in four Brazilian companies?. Journal of Cleaner Production, vol. 16, no. 17, pp. 1922-1925.

[31] A. A. Teixeira, C. J. C. Jabbour, and A. B. L. D. S. (2012). Jabbour. Relationship between green management and environmental training in companies located in Brazil: A theoretical framework and case studies. International Journal of Product and Economy, vol. 140, no. 1, pp. 318-329.

[32] K. H. Lee. (2009). Why and how to adopt green management into business organizations?: The case study of Korean SMEs in manufacturing industry. Manag. Decis., vol. 47, no. 7, pp. 1101-1121.

[33] K. Babiak and S. Trendafilova. (2011). CSR and environmental responsibility: motives and pressures to adopt green management practices. Corp. Soc. Responsib. Environ. Manag., vol. 18, no. 1, pp. 11-24.

[34] Brundtland GH. (1987). Our Common Future.World Commission on Environment and Development: Brussels.

[35] Hansmann, R. et al. (2012) Principal sustainability components: empirical analysis of synergies between the three pillars of sustainability. International Journal of Sustainable Development \& World Ecology, 19, pp. 451-459. 
[36] Daly, H.E. and Cobb, J.B. (1994) For the Common Good: Redirecting the Economy toward Community, the Environment, and a Sustainable Future. 2nd Edition, Beacon Press, Boston.

[37] J. Liu et al. (2015). Systems integration for global sustainability. Science, (80)., vol. 347, no. 6225.

[38] M. Wagner. (2014). A European perspective on country moderation effects: Environmental management systems and sustainability-related human resource benefits. J. World Bus., vol. 50, no. 2, pp. 379-388.

[39] M. S. and D. S. Beasley. (2015). Ermand sustainability: together on the road ahead. Showalter CPA, C.G.M.A. Strateg. Financ., vol. 96, no. 9, p. 32.

[40] Smith, P.A.C. and Sharicz, C. (2011). The shift needed for sustainability. The Learning Organization, Vol. 18 No. 1, pp. 73-86.

[41] Costello, A., Abbas, M., Allen, A., Ball, S., Bell, S., Bellamy, R., \& Patterson, C. (2009). Managing the health effects of climate change: Lancet and university college London Institute for global health commission. The Lancet, 373, 1693-1733.

[42] R. E. Freeman. (1984). Strategic Management: A Stakeholder Approach.

[43] Mitroff, I. (1983). Stakeholders of the Organizational Mind. San Francisco: JosseyBass.

[44] Elias, A. A., Cavana, R. Y. and Jackson, L. S. (2002). Stakeholder analysis for R\&D project management. R\&D Management 32 (4): 301 320.

[45] Bryson, J. M. (2003). What to Do When Stakeholders Matter: A Guide to Stakeholder Identification and Analysis Techniques. London School of Economics and Political Science.

[46] The Royal Malaysian Navy. (2014).

[47] Spence, M. (1973). Job market signaling. Quarterly Journal of Economics, 87, 355-374.

[48] B. L. Connelly, S. T. Certo, R. D. Ireland, and C. R. Reutzel (2011). Signaling theory: A review and assessment. Journal of Management. vol. 37, no. 1 , pp. 39-67.

[49] Spence, M. (2002). Signaling in retrospect and the informational structure of markets. American Economic Review, 92, 434-459.

[50] Stiglitz, J. E. (2002). Information and the change in the paradigm in economics. American Economic Review, 92: 460-501.

[51] Connelly, B. L., Certo, S. T., Ireland, R. D., \& Reutzel, C. R. (2011). Signaling Theory: A Review and Assessment. Journal of Management, 37(1), 39-67.

[52] Biron, M., Farndale, E., \& Paauwe, J. (2011). Performance management effectiveness: lessons from world-leading firms. The International Journal of Human Resource Management, 22(6), 1294-1311.

[53] Renwick, D. W. S., Redman, T., \& Maguire, S. (2013). Green Human Resource Management: A Review and Research Agenda. International Journal of Management Reviews, 15(1), 1-14.

[54] Dögl, C., \& Holtbrügge, D. (2014). Corporate environmental responsibility, employer reputation and employee commitment: an empirical study in developed and emerging economies. The International Journal of Human Resource Management, 25(12), 1739-1762.

[55] S. A. Taj (2016) Application of signaling theory in management research: Addressing major gaps in theory," Eur. Manag. J., vol. 34, no. 4, pp. 338-348.

[56] G. Mandip (2012) Green HRM: People management commitment to environmental sustainability. Research Journal of Recent Sciences. 